\title{
Call for Abstracts - 5th International Conference on Education in Ethics
}

Published online: 7 July 2016

(C) Springer International Publishing AG 2016

\section{5-17 November 2017}

Centre for Ethics, Yenepoya University, Mangalore, India

\section{CURRICULAR INNOVATIONS IN ETHICS EDUCATION}

The International Association for Education in Ethics (www.ethicsassociation.org) was established in 2011 as a platform to promote education in ethics at a global level.

The Centre for Ethics, Yenepoya University, Mangalore (www.yenepoya.edu.in) in India will host the fifth annual conference of the association in Nov 2017. Yenepoya University is the first university in the district of Dakshin Kannada (South Canara) situated in the western port town of Mangalore, a halcyon and picturesque town close to the heavenly states of Kerala and Goa.

The conference program includes plenary sessions, parallel sessions (oral) and poster presentations. Abstract (500 words maximum) submissions for oral and poster presentations are open from April 1, 2016 and the last date is December 31, 2016. The Conference Scientific Committee will select abstracts for oral/poster presentation. Please attach abstracts in the format given below by email to: Prof. Dr. Vina Vaswani, Director, Centre for Ethics, Yenepoya University, Mangalore, India. Email: abstract.iaee5@yenepoya.edu.in. For any other information, email to info.iaee5@yenepoya.edu.in.

Abstracts in English (MS Word, A4 size, default margins, Times New Roman or Arial, font size 12) are invited for topics in the following areas on ethics education: biotechnology ethics, business ethics, communication ethics, education ethics, engineering ethics, environmental ethics, ethics and biological sciences, ethics and law, ethics and professionalism, ethics and technology, healthcare ethics, research ethics, philosophical ethics, religious ethics, social sciences and ethics.

Structure your abstract using the following headings:

- Contact details of the author(s). Please mark the presenting author with an asterisk after name

- Family name, given names (as appearing in the passport)

- $\quad$ Title preferred (Prof/Dr/Mr/Ms/Prof. Dr)

- Current designation (if associated with an institution)

- Institution/university with postal address

- Address for communication: complete postal address with zip/pin 
- Contact details: current email, telephone number (optional)

- Abstract title

- Keywords (not more than five, separated by commas)

- Area of ethics education (see list above)

- Abstract body

- Background of the topic

- Aim/purpose

- Methods and/or philosophical perspective

- Results, outcomes and implications (Incomplete abstracts cannot be accepted)

- Conclusion

- Audio/visual equipment needed (Yes/No)

After review, you will be informed by email whether your abstract has been accepted. Selected abstract can be orally presented (maximum $20 \mathrm{~min}$ including Q\&A). 